\title{
Investigation of Separation Non-Persistent Faults in Fracture Mechanism of Rock Bridge
}

\author{
N.Nohekhan Hokmabadi ${ }^{a^{*}}$, V.Sarfarazi ${ }^{b}$, M.R.Moshrefifar $^{c}$ \\ ${ }^{a}$ M.Sc. Student, Geology Group, Yazd University, Yazd, Iran \\ ${ }^{b}$ Assistant Professor, Mining Engineering Division, Hamedan University of Technology, Hamedan, Iran \\ ${ }^{c}$ Assistant Professor, Geology Group, Yazd University, Yazd, Iran
}

Received 25 May 2016; Accepted 20 July 2016

\begin{abstract}
Rock mass is a heterogeneous material included joints, fractures and faults. The necessity of rock mechanics studies in conducting constructional issues has become important due to the increase in constructional works and the expansion of the structure's dimension and especially creating underground spaces in rock masses. Faults are the most important discontinuous fractures in the earth's crust in which the two sides of the fracture have moved relative to each other. The purpose of this research is that if the non-persistent faults were situated adjacent to each other, how would be the shear failure mechanism of Rock Bridge surrounded between the faults. For this purpose, physical model consisting two horizontal edge faults and a surrounded angled fault was built; angularity of the central fault varies from $0^{\circ}$ to $60^{\circ}$ with increasing the $30^{\circ}$. The central fault places in 3 different positions. Along the lateral faults, $1.5 \mathrm{~cm}$ vertically far from the edge faults and $3 \mathrm{~cm}$ vertically far from the edge faults. All samples tested by uniaxial test machine so that shear load was distributed in the specimens due to special geometry of specimen. The results show that the failure pattern was mostly influenced by configuration of central joint, while the shear strength was linked to the failure pattern and failure mechanism.
\end{abstract}

Keywords: Discontinuous; Non-Persistent; Rock Bridge; Uniaxial Test; Shear Behavior.

\section{Introduction}

Rock structures are not usually limited to a single discontinuity [1]. In other words, a series of discontinuities are located next to each other and create a combined shear failure surface [2]. Meanwhile, the areas between the adjacent discontinuity areas containing rocks are called Rock Bridge, and are of a high importance regarding shear resistance along the joint fraction plane [3]. The size and exact location of the rock bridge is barely recognizable in the rock mass and is often ignored in designing rock mechanics. The reason for the claim that rock bridges are a resistance source in shear surface is that before the shear occurs across the shear surface, these rock components break at first and the crack made by this fraction spread to the joints of the adjacent sections [4]. Since rock bridges indicate resistance to fracturing, the resistance of the sliding surface is greater than the state that the joint is continuous. Therefore, most of the civil projects, which have been designed assuming the continuity of the joints, suffer high costs to increase reliability coefficient. This is while the identification of the rock bridges along the sliding surface and investigating the resistance of the fracture surface, can increase reliability coefficient and lead to lower costs. Crack propagation and coalescence processes primarily cause rock failure in slopes, foundation and tunnels. Since Griffith (1921) studied the growth of pre-existing two-dimensional crack, many studies performed on the initiation, propagation and coalescence of crack. The studies that performed on jointed rock can help explain the joint propagation mechanism and server as model for the behavior of joint rock masses. Joint propagation and coalescence can reduce the stiffness of jointed rock masses causing the shear failure of rock slopes [5]. Also joint propagation and coalescence can induce earthquakes by

\footnotetext{
*Corresponding author: nasimhokmabadi@gmail.com
} 
forming shear faults [6]. A number of studies were performed on crack propagation in different materials under uniaxial compression. Lajtai (1969) performed direct shear test on natural rock specimens with two parallel slots [7]. Segall and Pollard (1980) conducted analytical on the stress field in rock bridges between two stepped cracks [8]. Horri and Nemat-Naser (1986) investigation the coalescence behavior of multi-cracks in polymer specimens [9]. Reyes and Einstein (1991) [10] performed uniaxial tests on gypsum specimens with two inclined flaws and Shen et al. (1995) [11] conducted uniaxial tests on gypsum with two cracks. Wong (2001) analyzed of crack coalescence in rocklike materials containing three flaws. Three flaws are arranged such that one pair of flaws lines collinearly and the third flaw forms either a non-overlapping pattern or an overlapping pattern with the first flaw. It is found that the mechanisms of crack coalescence depend on the flaw arrangement and the friction coefficient on the flaw surface. Two "rules of failure" for the specimens containing three flaws are proposed. Rule No.1: the pair of flows with a lower value of coalescence stress will dominate the process of coalescence. Rule N0.2: mixed and tensile modes of coalescence are always the dominant modes if the coalescence stress of the two pairs of flaws is very close [12]. Mughieda (2004) studied fracture mechanisms of offset rock joints in laboratory. Results showed that open crack could coalesce by shear failure or tensile failure. The coalescence path was found to be mainly dependent on the inclination of the rock bridge between the cracks. Gehle (2003) performed breakage and shear behavior of intermittent rock joints [13]. Park and Bobet (2010) studied crack initiation, propagation and coalescence from frictional flaws in uniaxial compression. The most important conclusion reached in this research is that the fracturing processes in open and closed flaws are similar [14]. Ping Cao (2015) performed crack propagation and coalescence of brittle rock-like specimens with pre-existing crack in compression [15]. Also Ping Zhang (2015) studied crack coalescence between two non-parallel flaws in rock-like material under uniaxial compression [16]. However, all those studied were conducted on small size sample and on limited types of test materials. In previous works, the failure mechanism of rock bridge in a single layer has been investigated. In this paper the failure pattern and failure mechanism of nonpersistent faults situated in two different layers was studied.

\section{Specimen Preparation and Testing}

\subsection{Specimen Preparation}

Two type of mixture were prepared. In first type of mixture, the water and gypsum were mixed with a ratio of water to gypsum $=0.6$. In second type of mixture, the water, sand and cement were mixed with a ratio of $27 \%, 33 \%$ and $40 \%$. Molding and implementing the specimens was done carefully to obtain homogeneous and isotropic samples. This slurry was poured into special mold (Figure 1.a). This mold was consisted of three different boxes. During the molding, the mold was vibrated so that air bubbles were removed from the specimen. To create pre-existing cracks in the specimens, the metal blades with thickness of $1 \mathrm{~mm}$, wide of $20 \mathrm{~mm}$ to $30 \mathrm{~mm}$ and length of $140 \mathrm{~mm}$ were used. Two blades with width of $30 \mathrm{~mm}$ were placed in the lateral boxes and blade with width of $20 \mathrm{~mm}$ was placed in the central box (Figure 1.b). It's to be note that the central shim was situated in three different situations, i.e. along the edge joints; $1.5 \mathrm{~cm}$ far from symmetrical line and $3 \mathrm{~cm}$ far from symmetrical line. The angle of central joint varied from $0^{\circ}$ to $60^{\circ}$ with increment of $30^{\circ}$. Totally 9 specimen were prepared for investigation of shear behavior of nonpersistent joint. The geometry of specimen was listed in table 1 . The length of the marginal faults is $30 \mathrm{~mm}$ and the length of the central fault is $20 \mathrm{~mm}$ and the opening of the faults is $1 \mathrm{~mm}$. After 24 hours of casting, the specimens were removed from the mold and were kept in the laboratory at room temperature of $20^{\circ} \pm 2$ for 14 days and then were tested under uniaxial test.

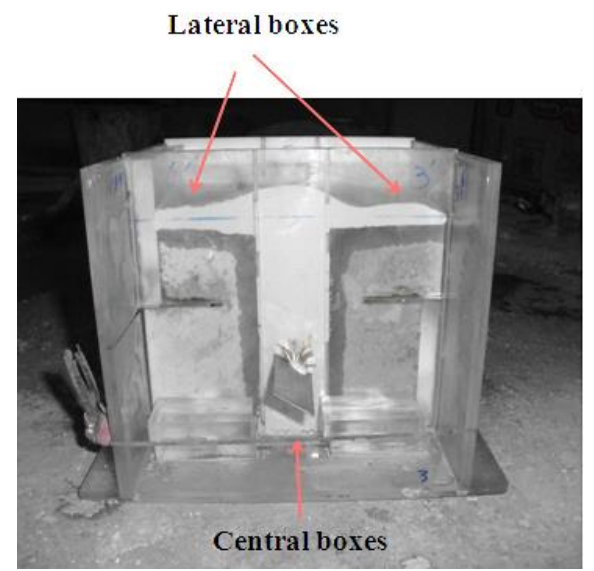

(a)

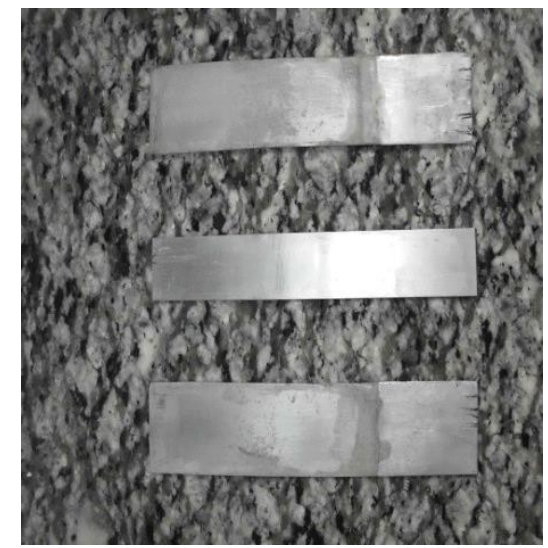

(b)

Figure 1. a) The special mold, b) Used steel blades for create gap in specimens 
Table1. Geometric features of the specimens containing non-persistent faults

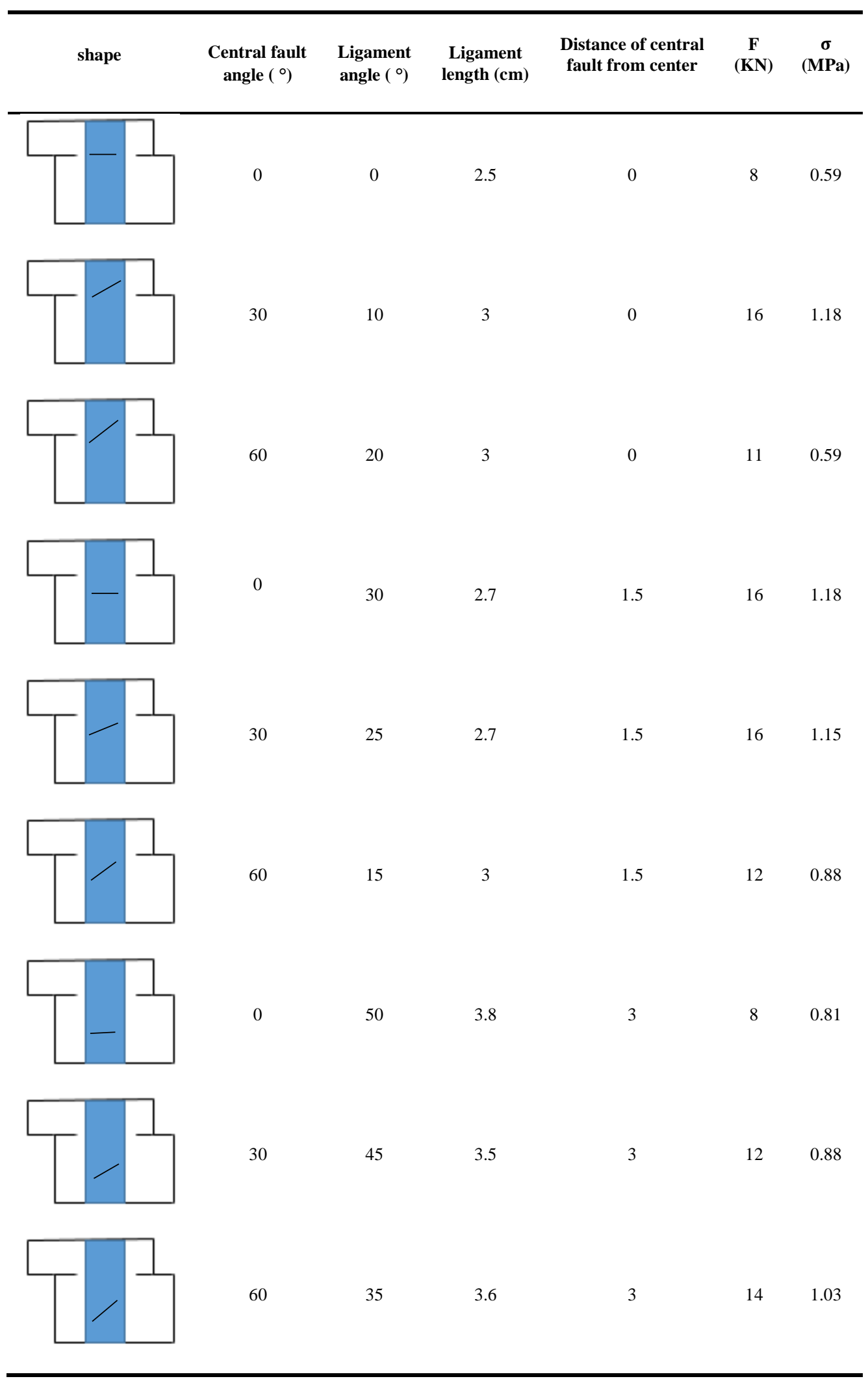

\subsection{Test Machine}

The test was performed using a $2000 \mathrm{KN}$ Universal Compression Machine. All samples were tested by applying a normal displacement rate of $0.01 \mathrm{~mm} / \mathrm{s}$. The normal loads as well as the axial displacements were taken by a data acquisition system during the test. The normal load distributed as shear load on the rock bridge areas (Figure 2). 


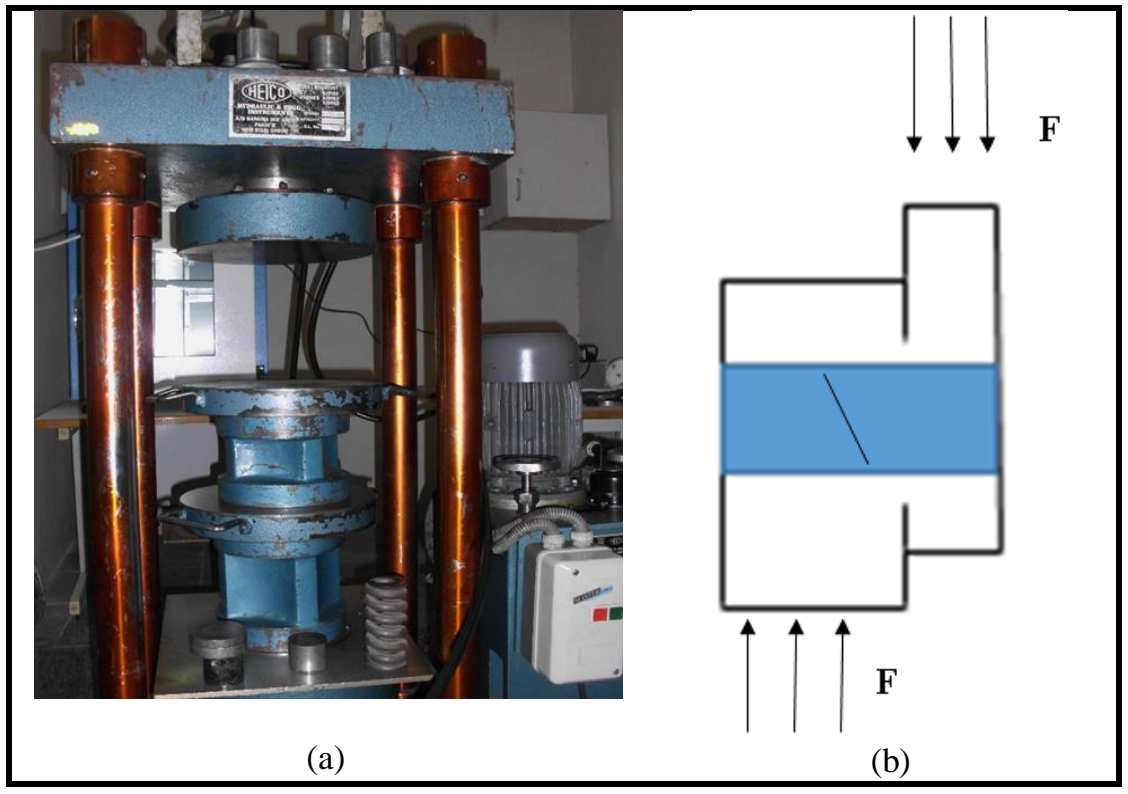

Figure 2. a) View of the uniaxial machine, b) the schematic view of shear loading

\section{Results and Discussion}

The inspestion of failure surface shows that this surface was smooth without any crushed or poluverized material. This is a good evidence for tensile failure mode occurrence in in all of the samples.

\section{a) When central fault was situated along the two edge faults with an angularity of $0^{\circ}$ :}

The length of each rock bridge on both sides of the central fault is $2.5 \mathrm{~cm}$. The crack initiates from tip of the marginal fault and propagates horizontally toward the central faults. By increasing the normal loading, the cracks reach to the gypsum-cement boundryies and growth diagonally with direction of $20^{\circ}$ related to vertical line. These cracks coalesce with tips of central fault. This coalescene left two oval core of cement/gepsum materials. Its to be note that the lyers were separated from each other after the test (Figure 3).

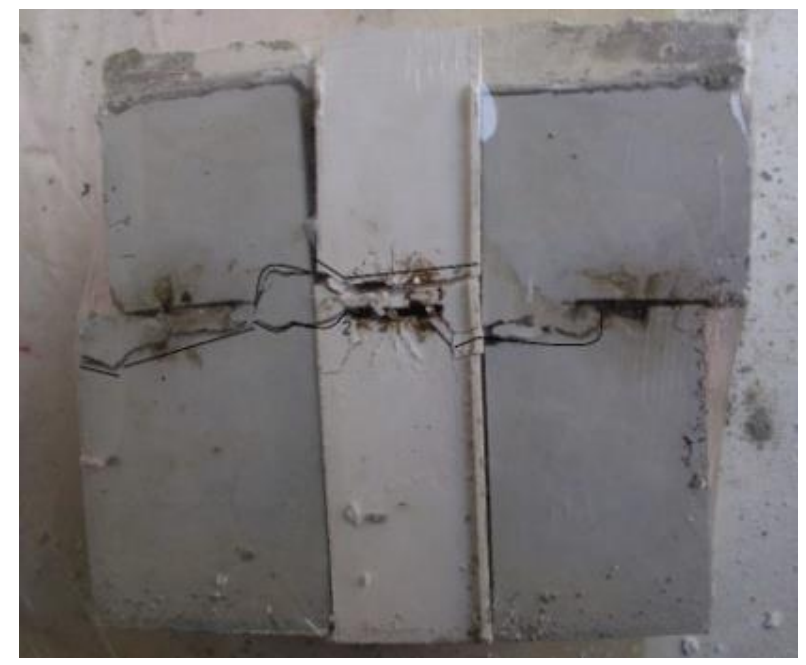

Figure 3. Failure mode in specimen when central fault was situated along the two edge faults with an angularity of $0^{\circ}$

\section{b) When central fault was situated $1.5 \mathrm{~cm}$ far from the edge faults with an angularity of $0^{\circ}$ :}

In this configuration, crack initiated form tip of the left edje joint and propagate with direction of 45 degree related to vertical line. This crack reach to the gypsum-cement boundry and then propagates horizontaly till coalescethe with the tip of the central fault. Other crack initiates from edge of the sample and propagates toward the gypsum-cement boundry. This crack grow horizontally in gypsum material till rotate vertically and coalese with central jopint. This coalesence left an echelon failure in the sample (Figure 4). 


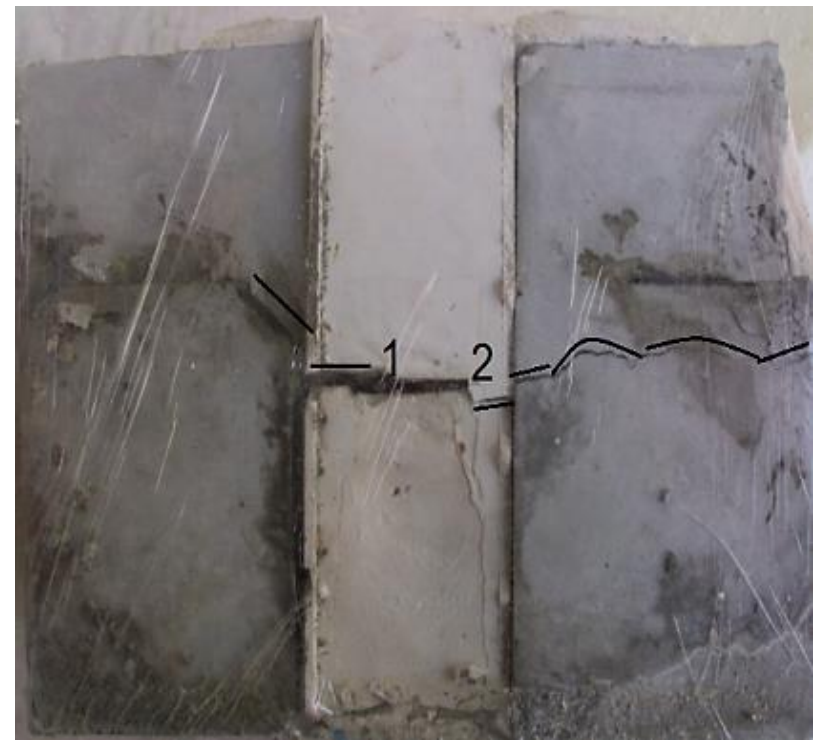

Figure 4. Failure mode in specimen when central fault was situated $1.5 \mathrm{~cm}$ far from the edge faults with an angularity of 0

\section{c) When central fault was situated $3 \mathrm{~cm}$ far from the edge faults with an angularity of $0^{\circ}$ :}

The rock bridge on both sides of the central fault is $3 \mathrm{~cm}$. In this configuration, crack initiated form tip of the left edje joint and propagate horizontally till coalesce with right side of the cement-gypsum boundry. This crack propagates with direction of 30 degree related to horizontal line and coalesse with left side of cement-gypsum boundry. Other crack initiates from tip of the right edje joint and propagates toward the right side of the gypsumcement boundry with direction of -10 degree related to horizontal line. This crack grow in gypsum with direction of 10 degree related to horizontal line and coalese with other crack tip. This coalesence left an wavy failure surface in the sample (Figure 5).

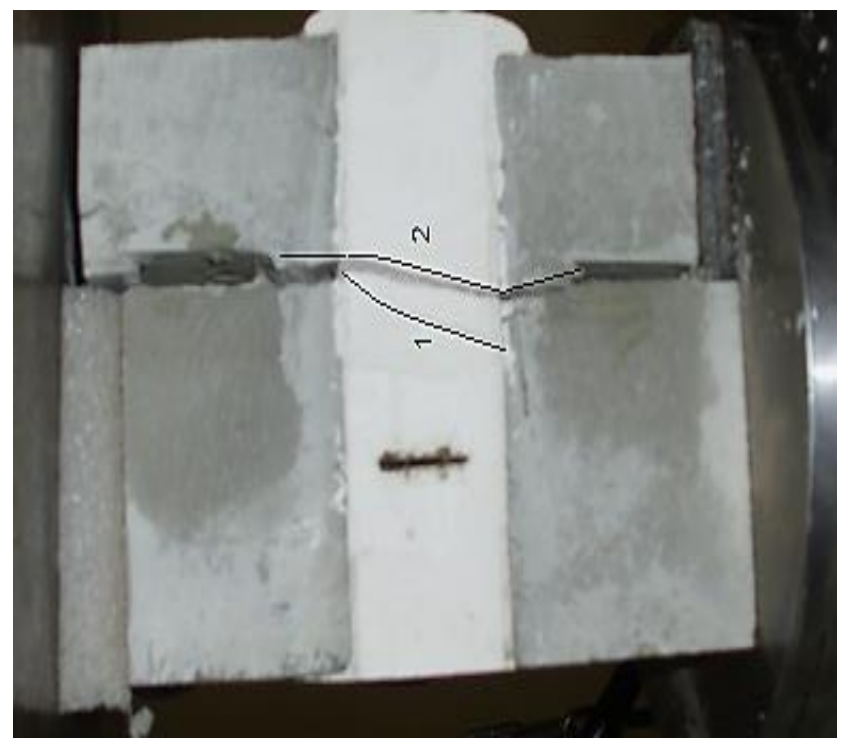

Figure 5. Failure mode of specimen when central fault was situated $3 \mathrm{~cm}$ far from the edge faults with an angularity of $0^{\circ}$

\section{d) When central fault was situated along the two edge faults with an angularity of $30^{\circ}$ :}

The length of each rock bridge on both sides of the central fault is $3 \mathrm{~cm}$. In this configuration, crack initiated form tip of the right edje joint and propagate horizontally along the joint plane. This crack reach to the gypsum-cement boundry and then propagates horizontaly till coalescethe with the tip of the central fault. Other crack initiates from edge of the sample and propagates toward the gypsum-cement boundry. This crack grow horizontally in gypsum material till coalese with central joint tip. This coalesence left a wavy failure surface in the sample (Figure 6). 


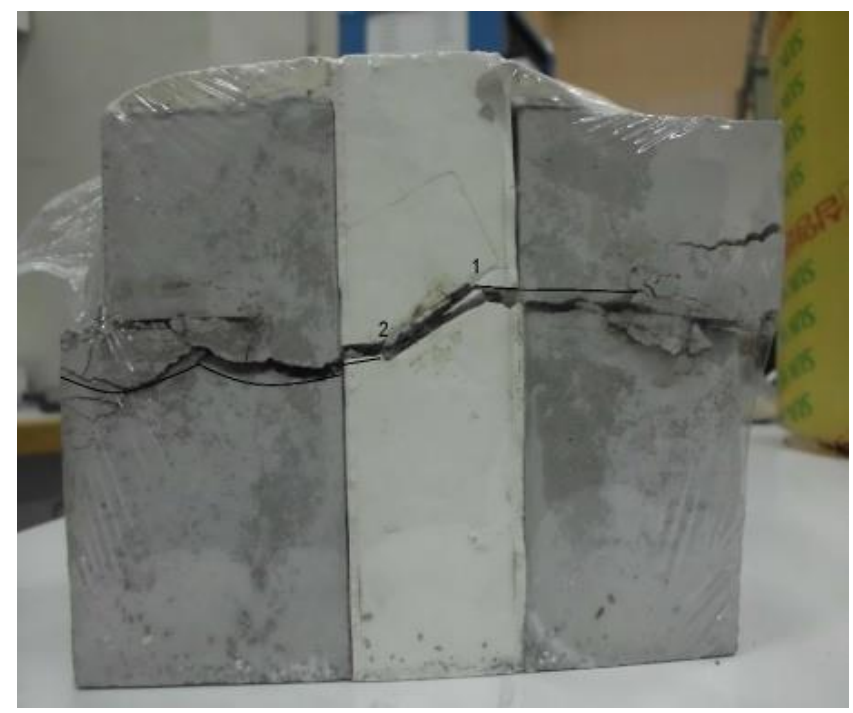

Figure 6. Failure mode of specimen when central fault was situated along the two edge faults with an angularity of $30^{\circ}$

\section{e) When central fault was situated $1.5 \mathrm{~cm}$ far from the edge faults with an angularity of $30^{\circ}$ :}

In this configuration, crack was initiated form tip of the right edje joint and propagate with direction of 45 degree related to horizontal line. This crack reach to the gypsum-cement boundry and then propagates with direction of -45 degree related to horizontal line till coalescethe with the tip of the central fault. Other crack initiates from left joint wall. The crack initiation angle was 25 degree. This crack propagates parallel to shear load direction till reach to the gypsum-cement boundry. A new crack initiats in a lower part and propagats horizontally in gypsum material till coalese with central joint tip. This coalesence left a wavy failure surface in the sample (Figure 7).

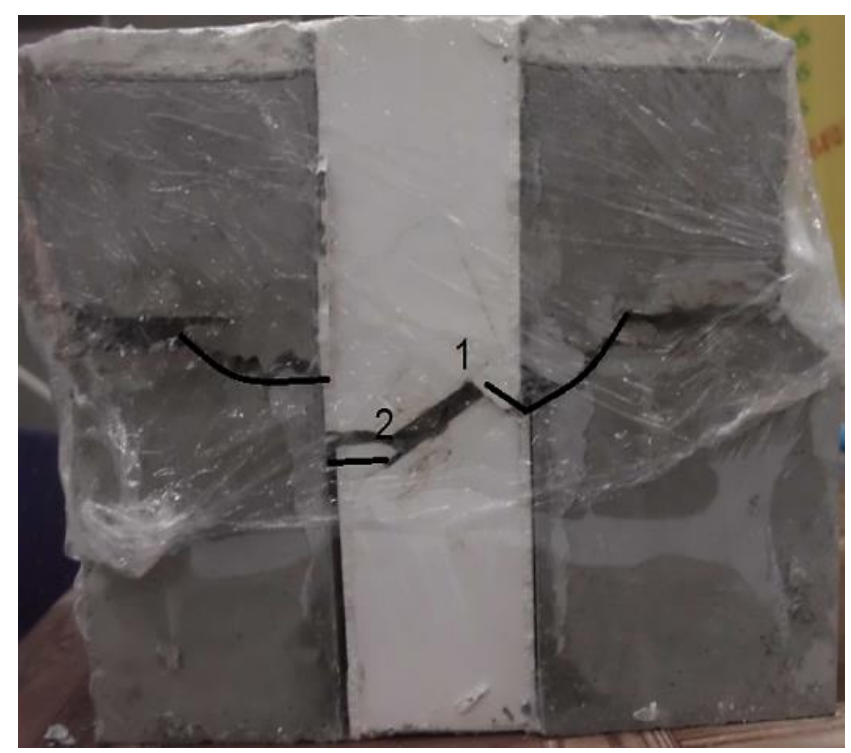

Figure 7. Failure mode of specimen when central fault was situated $1.5 \mathrm{~cm}$ far from the edge faults with an angularity of $30^{\circ}$

\section{f) When central fault was situated $3 \mathrm{~cm}$ far from the edge faults with an angularity of $30^{\circ}$ :}

In this configuration, crack was initiated form tip of the right edje joint and propagate with direction of 45 degree related to horizontal line. This crack reach to the gypsum-cement boundry and then propagates with direction of 45 degree related to horizontal line till coalesce with upper tip of the central fault. Other crack initiates from left edge of the sample. This crack propagates parallel to shear load direction till reach to the gypsum-cement boundry. A new crack initiats in a lower part and propagats horizontally in gypsum material till coalese with upper tip of the central joint tip. This coalesence left a wavy failure surface in the sample (Figure 8). In this failure just the upper tip of the central joint tip participat in failure phenomena. 


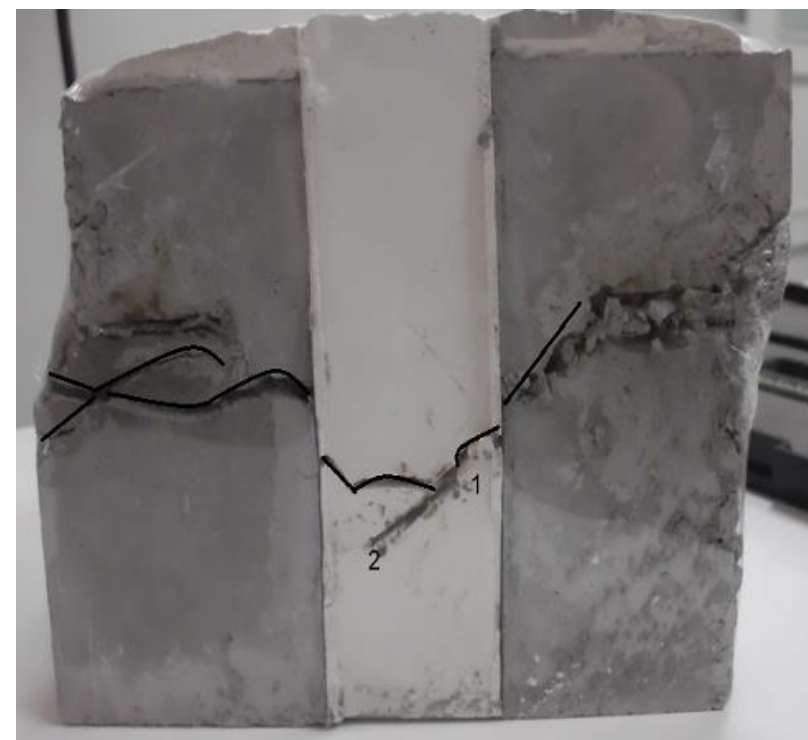

Figure 8. Failure mode of specimen when central fault was situated $3 \mathrm{~cm}$ far from the edge faults with an angularity of $30^{\circ}$

\section{g) When central fault was situated along the two edge faults with an angularity of $60^{\circ}$ :}

In this configuration, cracks were initiated form tips of the edje joints and propagate with direction of 45 degree related to horizontal line. This crack reach to the gypsum-cement boundry and then propagates with direction of 45 degree related to horizontal line till coalescethe with the tips of the central fault. This coalesence left a wavy failure surface with sharp edge in the sample (Figure 9).

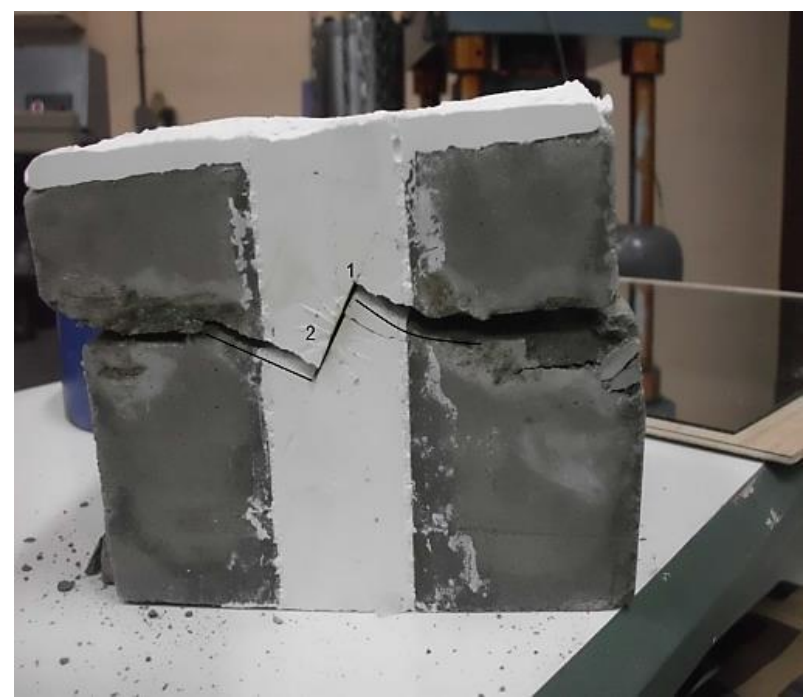

Figure 9. Failure mode of specimen when central fault was situated along the two edge faults with an angularity of $60^{\circ}$

\section{h) When central fault was situated $1.5 \mathrm{~cm}$ far from the edge faults with an angularity of $60^{\circ}$ :}

In this configuration, crack was initiated form tip of the right edje joint and turn downward after small propagation. This crack grow with direction of 15 degree related to horizontal line and reach to the gypsum-cement boundry. A new crack develope from the gypsum-cement boundry and propagate in a same direction till coalese with upper tip of the central joint. Other crack initiats from tip of the left join and propagate with direction of 25 degree related to horizontal line. This crack reach to the gypsum-cement boundry and then propagates with same direction till coalescethe with wall of the central fault. This coalesence left a steped failure surface in the sample (Figure 10). 


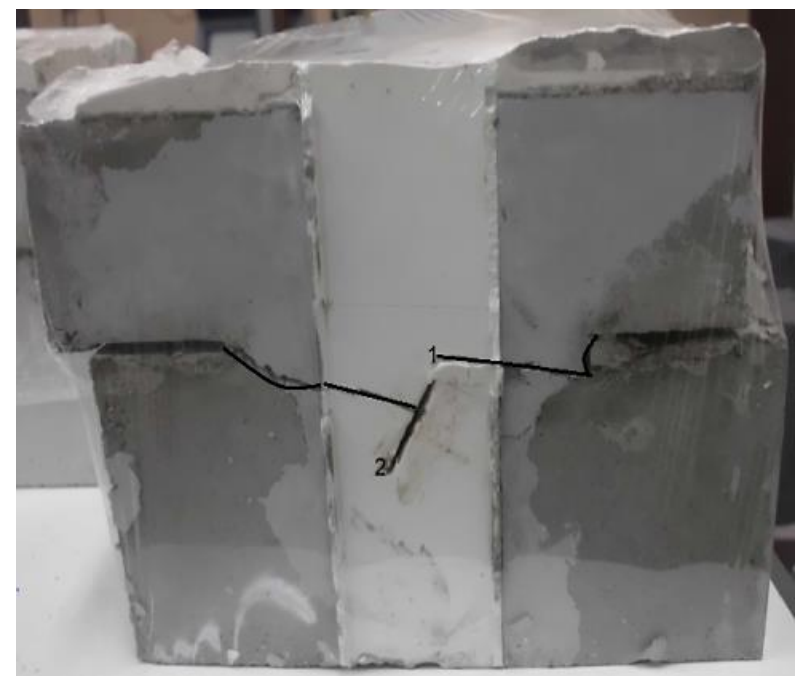

Figure 10. Failure mode of specimen when central fault was situated $1.5 \mathrm{~cm}$ far from the edge faults with an angularity of $60^{\circ}$

\section{i) When central fault was situated $3 \mathrm{~cm}$ far from the edge faults with an angularity of $60^{\circ}$ :}

In this configuration, crack was initiated form tip of the right edje joint and propagate with direction of 30 degree related to horizontal line. This crack reach to the gypsum-cement boundry. A new crack initiats in a lower part and propagats with direction of 30 degree related to horizontal line till coalese with upper tip of the central joint tip. Other crack initiates from left edge of the sample. This crack propagates nearly parallel to shear load direction till reach to the gypsum-cement boundry. A new crack initiats in a lower part and propagats diagonally in gypsum material till coalese with lower tip of the central joint tip. This coalesence left a wavy failure surface in the sample (Figure 11).

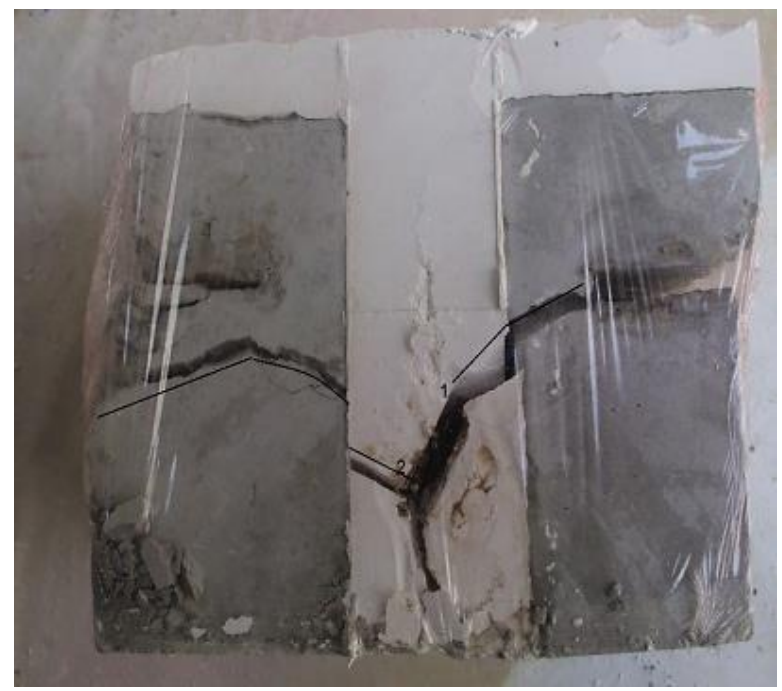

Figure 11. Failure mode of specimen when central fault was situated $3 \mathrm{~cm}$ far from the edge faults with an angularity of $60^{\circ}$

The specimens were analyzed in terms of shear strength. The Figures 12, 13 and 14 show differences of shear strength in different angles and in three positions. Angle of $30^{\circ}$ in $a=0$, has maximum value of shear strength and angle of $0^{\circ}$ in $a=0$ and $a=1.5 \mathrm{~cm}$, has minimum value of shear strength. 


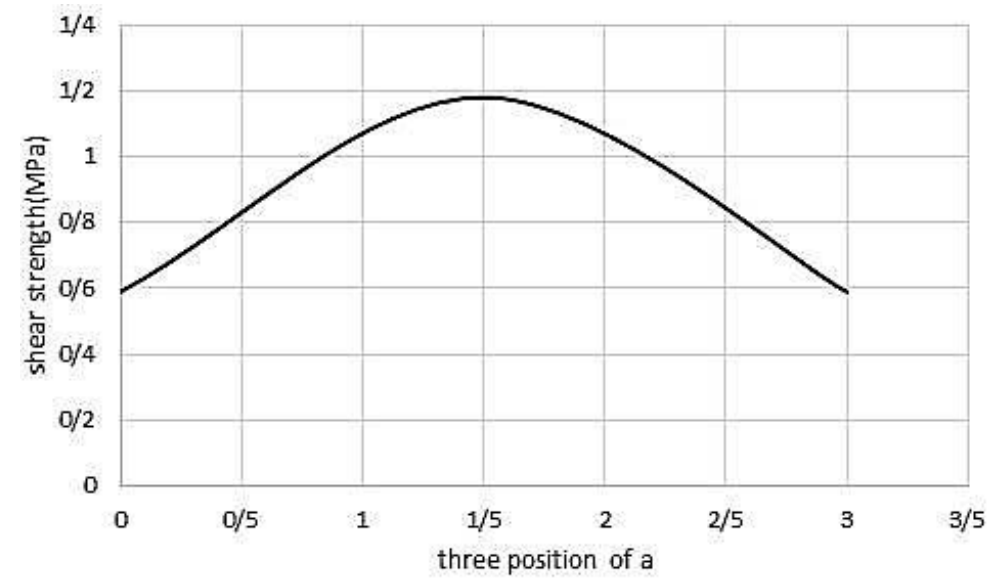

Figure 12. Shear strength of angle $0^{\circ}$ in different three position of a

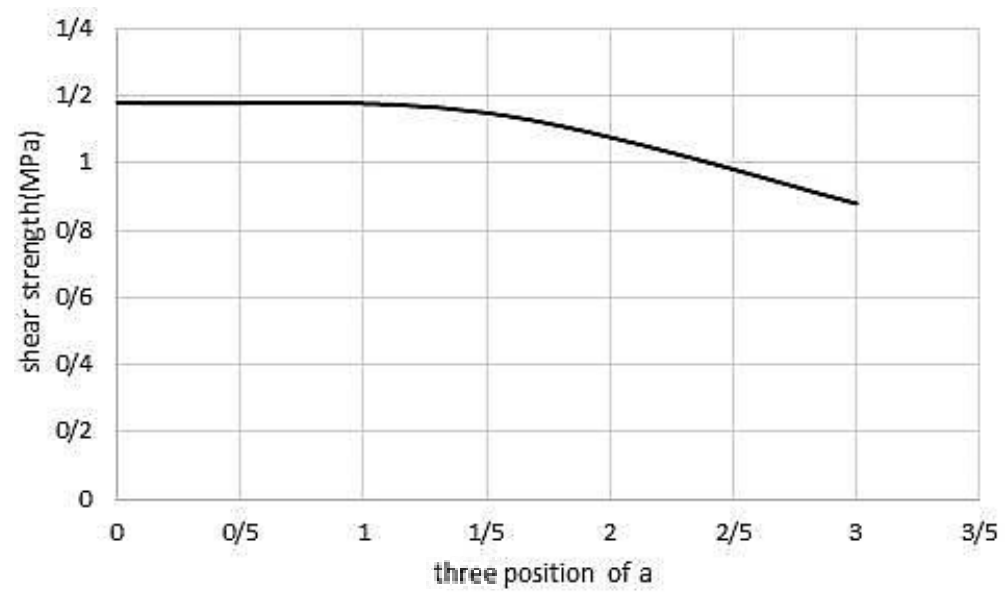

Figure 13. Shear strength of angle $30^{\circ}$ in different three position of a

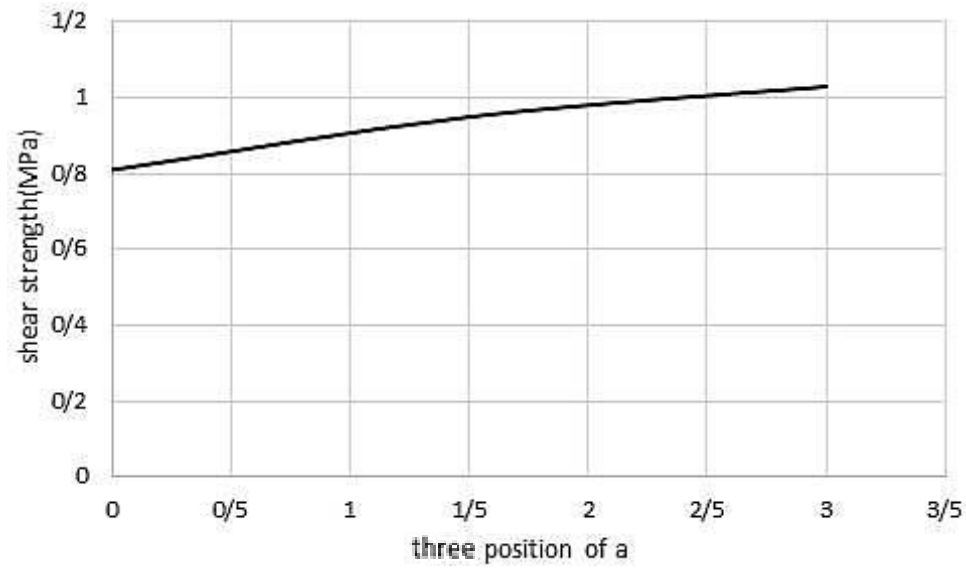

Figure 13. Shear strength of angle $60^{\circ}$ in different three position of a

\section{Conclusion}

Based on the test results it can be found that:

- With increasing the distance between the edge joints and central joint, the failure patter was confidence to edge joints.

- Tensile crack was dominant mode of failure.

- The failure patterns were nearly similar when central joint was placed along the lateral faults and or $1.5 \mathrm{~cm}$ vertically far from the edge faults.

- The failure surface was wavy.

- With increasing the central joint angularity, the waviness of failure surface was increased 


\section{References}

[1] National Research Council (US). Committee on Fracture Characterization, and Fluid Flow. Rock fractures and fluid flow: contemporary understanding and applications. National Academies Press, 1996.

[2] Jaeger, J. C. "Friction of rocks and stability of rock slopes." Geotechnique 21, no. 2 (1971): 97-134.

[3] Glynn, E. F., D. Veneziano, and H. H. Einstein. "The probabilistic model for shearing resistance of jointed rock." In 19th US Symposium on Rock Mechanics (USRMS). American Rock Mechanics Association, 1978.

[4] Stimpson, B. "Failure Of Slopes Containing Discontinuous Planar Points." In 19th US Symposium on Rock Mechanics (USRMS). American Rock Mechanics Association, 1978.

[5] Mughieda, Omer, and Abdel Kareem Alzo'ubi. "Fracture mechanisms of offset rock joints-A laboratory investigation." Geotechnical \& Geological Engineering 22, no. 4 (2004): 545-562.

[6] Deng, Qidong, and Peizhen Zhang. "Research on the geometry of shear fracture zones." Journal of Geophysical Research: Solid Earth 89, no. B7 (1984): 5699-5710.

[7] Lajtai, E. Z. "Strength of discontinuous rocks in direct shear." Geotechnique 19, no. 2 (1969): 218-233.

[8] Segall, Paul, and D. D. Pollard. "Mechanics of discontinuous faults." Journal of Geophysical Research: Solid Earth 85, no. B8 (1980): 4337-4350.

[9] Namat-Nasser, S., and H. Horii. "Compression-induced non-planar crack extension with application to splitting, exfoliation and rockbursts." Geophys Res J (1982): 6805-21.

[10] Reyes, O., H. H. Einstein, and V. C. Li. "Stochastic and centrifuge modeling of jointed rock." Part I-Fracturing of jointed rock, Final Report submitted to the Air Force Office of Scientific Research and Air Force Engineering Services Center, USA (1990).

[11] Shen, Baotang, Ove Stephansson, Herbert H. Einstein, and Bidjan Ghahreman. "Coalescence of fractures under shear stresses in experiments." JOURNAL OF GEOPHYSICAL RESEARCH-ALL SERIES- 100 (1995): 5975-5975.

[12] Wong, R. H. C., K. T. Chau, C. A. Tang, and P. Lin. "Analysis of crack coalescence in rock-like materials containing three flaws - part I: experimental approach." International Journal of Rock Mechanics and Mining Sciences 38, no. 7 (2001): $909-924$.

[13] Gehle, C., and H. K. Kutter. "Breakage and shear behaviour of intermittent rock joints." International Journal of Rock Mechanics and Mining Sciences 40, no. 5 (2003): 687-700.

[14] Park, C. H., and A. Bobet. "Crack coalescence in specimens with open and closed flaws: a comparison." International Journal of Rock Mechanics and Mining Sciences 46, no. 5 (2009): 819-829.

[15] Cao, Ping, Taoying Liu, Chengzhi Pu, and Hang Lin. "Crack propagation and coalescence of brittle rock-like specimens with pre-existing cracks in compression." Engineering Geology 187 (2015): 113-121.

[16] Zhang, Xiao-Ping, Quansheng Liu, Shunchuan Wu, and Xuhai Tang. "Crack coalescence between two non-parallel flaws in rock-like material under uniaxial compression." Engineering Geology 199 (2015): 74-90. 